Original Research Paper

\title{
Wettability and Interfacial Tension Alteration of Rare-Earth Doped Yttrium Iron Garnet under Influence of Electromagnetic Waves
}

\author{
${ }^{1}$ Lau Zhen Yin, ${ }^{1}$ Lee Kean Chuan, ${ }^{1}$ Beh Hoe Guan, ${ }^{1}$ Hassan Soleimani and ${ }^{2}$ Martin Weis \\ ${ }^{1}$ Fundamental and Applied Sciences Department, Universiti Teknologi PETRONAS, Bandar Seri Iskandar, Malaysia \\ ${ }^{2}$ Institute of Electronics and Photonics, Slovak University of Technology, Ilkovicova 3, 81219 Bratislava, Slovakia
}

Article history

Received: 16-04-2019

Revised: 09-07-2019

Accepted: 24-07-2019

Corresponding Author:

Lee Kean Chuan

Fundamental and Applied

Sciences Department,

Universiti Teknologi

PETRONAS, Bandar Seri

Iskandar, Malaysia

Email: lee.kc@utp.edu.my

\begin{abstract}
Yttrium Iron Garnet (YIG) doped with rare-earth elements have shown to alter the magnetic properties of garnet nanoparticles (NPs), which is believed to have direct influence on the wettability, interfacial tension and viscosity alteration of garnet nanofluids. In this study, $\mathrm{Y}_{2.8} \mathrm{R}_{0.2} \mathrm{Fe}_{5} \mathrm{O}_{12}(\mathrm{R}$ $=$ Lanthanum $(\mathrm{La})$, Neodymium $(\mathrm{Nd})$ and Samarium $(\mathrm{Sm})$ ) NPs were synthesized by using the sol gel auto-combustion method followed by annealing treatment at $1000^{\circ} \mathrm{C}$ for 3 hours. The $\mathrm{Y}_{2.8} \mathrm{RE}_{0.2} \mathrm{Fe}_{5} \mathrm{O}_{12}$ nanoparticles synthesized had grain size ranging from 100 to $200 \mathrm{~nm}$ with high crystallinity properties. X-ray Diffraction peaks showed varying shifting with the size of the rare-earth ions in the $\mathrm{Y}_{2.8} \mathrm{R}_{0.2} \mathrm{Fe}_{5} \mathrm{O}_{12}$ crystal system, suggesting that structural distortion is due to replacement of bigger ions. Sm-YIG exhibited the highest magnetization saturation among all samples, with the value of $23.54 \mathrm{emu} / \mathrm{g}$. Wettability data of $\mathrm{Y}_{2.8} \mathrm{R}_{0.2} \mathrm{Fe}_{5} \mathrm{O}_{12}$ (RE-YIG) nanofluids showed that oil-wetting contact angle has an overall reduction under the influence of electromagnetic wave. Whereas the interfacial tension and viscosity data showed that doped garnet nanofluids has lower value than that of garnet nanofluids, but the magnitude of interfacial tension and viscosity value decreased with the rare-earth ionic size. Sm-YIG also has the highest interfacial tension across all samples, as the stronger magnetization saturation may contribute to higher surface tension exerted on the oil-nanofluid interface.
\end{abstract}

Keywords: Rare-Earth, Garnets, Nanoparticles, Wettability

\section{Introduction}

Enhanced Oil Recovery (EOR) using Nanoparticles (NPs) method has been a major novel application research topic to further improve current oil recovery rate. According to Bennetzen and Mogensen (2014) and Peng et al. (2017), nanoparticles has shown promising solution to both upstream and downstream of oil and gas field, among which are the ability to alter wettability, Inter Facial Tension (IFT) and viscosity of the multiphase fluids within the reservoir formation. Injection of nanoparticles as nanofluids into reservoir formation under the influence of Electromagnetic (EM) wave, will activate the nanoparticles to cause thermodynamics disturbance within the reservoir structure (Bhatia and Chacko, 2011). Low dimensionality of nanoparticles enhances the magnetization or became paramagnetic, which makes alteration of surface force of fluids achievable (Pilkington and Wuge, 2012) and improve the recovery rate through oil-water IFT reduction (Soleimani et al., 2018). To further improve oil recovery rate, the magnetic aspect of nanoparticles is crucial. Oscillating magnetization forces experienced by the magnetic nanoparticles has shown to initiate interfacial movement at the oil-water interface and altering the apparent viscosity of the nanofluids due to their magnetorheological and electrorheological properties, which improve the oil mobilization rate (Ryoo et al., 2012; Yahya, et al., 2014; Zaid et al., 2014; Zitha and Wessel, 2002). Soares et al. (2014) simulation study, high magnetic susceptibility nanoparticles were recommended as the magnetic perturbation caused by nanoparticles within the pore wall will facilitate oil blob detachment, thus improving the oil recovery rate. As studied by Soleimani et al. (2014), higher magnetic susceptibility nanoparticles shown better oil recovery rate in a core flooding test under EM wave irradiance. 
A core flooding test with Yttrium Iron Garnet (YIG) nanofluid with the presence of EM waves has shown a yield of $43.64 \%$ (Soleimani et al., 2016), making them a promising candidate for the application. Rare-Earths (RE) doped YIG has shown promising ability to alter the magnetic properties of YIG, changing the structural, morphological and dielectric properties as well (Akhtar et al., 2017). However, the dopant alteration of the magnetic properties of YIG is dependent on the magnetic moment of both rare-earth ions and yttrium ions, observed neodymium doped YIG has a higher magnetic property than YIG (Wolf, 1961). Low dimensionality of YIG nanoparticles shows superparamagnetic behavior with high magnetic susceptibility as well (Sanchez et al., 2002).

In this study, Lanthanum (La), Neodymium (Nd) and Samarium (Sm) were doped into YIG at the concentration of 0.2 moles to form $\mathrm{Y}_{2.8} \mathrm{R}_{0.2} \mathrm{Fe}_{5} \mathrm{O}_{12}$ (RE-YIG) NPs. The samples were synthesized via sol-gel auto-combustion method and characterized by Field-Emission Scanning Electron Microscope (FESEM), Energy-dispersive X-ray spectroscopy (EDX), X-ray Diffractometer (XRD) and Vibrating Sample Magnetometer (VSM). The properties of RE-YIG nanofluids were evaluated through inverted sessile drop method for contact angle and IFT measurements. Viscosity of the RE-YIG nanofluids was performed using a rheometer. All nanofluids properties were investigated with or without the presence of EM waves at $100 \mathrm{MHz}$. The aim of the study is to relate the wettability, IFT and viscosity of RE-YIG nanofluid with the magnetization properties under the influence of EM waves.

\section{Experimental Methodology}

\section{Materials and Methods}

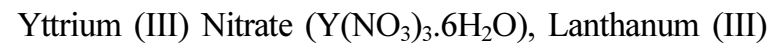
Nitrate, Neodymium (III) Nitrate, Samarium (III) Nitrate and Iron (III) Nitrate $\left(\mathrm{R}\left(\mathrm{NO}_{3}\right)_{3} \cdot 6 \mathrm{H}_{2} \mathrm{O}\right)$ were used as raw material to synthesize the RE-YIG nanoparticles via sol-gel auto-combustion method. Citric acid was added as chelating agent at the ratio of metal nitrates to citrates to be $1: 1$ (Vajargah et al., 2007) and the $\mathrm{pH}$ of the mixture solution was adjusted to 2 using ammonia solution (Vajargah et al., 2006). The resulting solutions were then heated at $90^{\circ} \mathrm{C}$ and stirred with magnetic stirrer until a viscous gel is formed. The gels were then heated up to $250-300^{\circ} \mathrm{C}$ for combustion and the burnt powder were then grounded. Annealing treatment at $1000^{\circ} \mathrm{C}$ for $3 \mathrm{~h}$ were followed. For complete annealing treatment and the formation of single-phase high crystallinity YIG nanoparticles, high annealing temperature is required (Akhtar et al., 2014; Baqueiro et al., 1997; Janifer et al., 2017). Unlike ball milling methods, the mixtures of $\mathrm{Y}_{2} \mathrm{O}_{3}$ and $\alpha-\mathrm{Fe}_{2} \mathrm{O}_{3}$ powders in molar ratio $3: 5$ were ball-milled using a planetary mill and requires lesser amount of raw materials.
Table 1: Mass of each precursor material required Amount (g)

\begin{tabular}{lllll} 
& & & & \\
RE-YIG & Y & RE & Fe & Citric Acid \\
\hline YIG & 15.57 & 0.00 & 27.37 & 20.83 \\
Nd-YIG & 14.32 & 1.17 & 26.97 & 20.52 \\
La-YIG & 14.34 & 1.16 & 27.01 & 20.55 \\
Sm-YIG & 14.30 & 1.19 & 26.93 & 20.49 \\
\hline
\end{tabular}

However, the annealing temperature is higher $\left(1200^{\circ} \mathrm{C}\right)$ which leads to bigger grain size (Ristić et al., 2003). Table 1 depicts the amount of precursor materials needs in order to yield $10 \mathrm{~g}$ of YIG NPs.

\section{Characterization of RE-YIG Nanoparticles}

Once RE-YIG nanoparticles were synthesized, they were sent to FESEM coupled with EDX to characterize their morphology and element composition. XRD were then used to evaluate the phase and crystallinity of the synthesized RE-YIG nanoparticles. As for the magnetization properties of the samples, they were characterized using VSM.

\section{Evaluation of RE-YIG Nanofluids}

$0.01 \mathrm{wt} \%$ of RE-YIG nanoparticles were mixed with $30000 \mathrm{ppm}$ brine solution to form nanofluid samples (Ogolo et al., 2012). Appropriate amount of surfactant was added to increase the suspension time of the nanoparticles within the fluid. Once the nanofluids were prepared, their densities were measured using density bottle. For the evaluation of wettability and IFT, an inverted sessile drop method was used with the help of Goniometer to measure the oil-wetting contact angle and IFT of the oil-nanofluids interface, both with and without the irradiance of EM wave (Yuan and Lee, 2013). Viscosity of nanofluids were measured using rheometer with and without EM irradiance as well.

\section{Results and Discussions}

\section{Characterization of RE-YIG Nanoparticles}

Field Emission Scanning Electron Microscopy and Energy Dispersive X-ray Spectroscopy Characterization.

As shown in Fig. 1, the measure grain size of NPs synthesized were within the range of 100-200 nm. Along with the FESEM results, EDX data were collected and tabulated in Table 2. EDX results show the element composition of each sample matches well with the weight percent of rare-earths doped in YIG which is about 3\% corresponding to the 0.2 mole concentration.

Referring to ICDD PDF2 RDB database, it was found that YIG with chemical formula of $\mathrm{Y}_{3} \mathrm{Fe}_{5} \mathrm{O}_{12}$ (Reference code: 01-043-0507) with a cubic crystal system were formed along with small traces of YIG with chemical formula of $\mathrm{YFeO}_{3}$ (Reference code: 01086-0170) which is an orthorhombic crystal system. 
Lau Zhen Yin et al. / American Journal of Applied Sciences 2019, 16 (6): 192.199 DOI: 10.3844/ajassp.2019.192.199

\begin{tabular}{|c|c|c|c|c|}
\hline \multirow[b]{2}{*}{ Element } & \multicolumn{4}{|c|}{ Samples (Weight \%) } \\
\hline & YIG & La-YIG & Nd-YIG & Sm-YIG \\
\hline $\mathrm{Y}$ & 34.37 & 31.44 & 33.19 & 33.38 \\
\hline $\mathrm{Fe}$ & 29.89 & 30.95 & 26.05 & 30.18 \\
\hline $\mathrm{O}$ & 35.73 & 34.11 & 38.15 & 32.64 \\
\hline $\mathrm{R}$ & 0 & 3.49 & 2.61 & 3.8 \\
\hline
\end{tabular}

Figure 2 shows the XRD patterns of YIG and RE-YIG NPs respectively, where $h k l$ values were obtained from the database. High intensity peaks shown in Fig. 2 indicate high crystallinity properties of the NPs.

Based on the highest peak (420) of the spectrum, the $2 \theta$, Full-Width Half-Maximum (FWHM) and d-spacing values crystalline size was calculated using Scherrer equation:

$$
D=k \lambda / \beta \cos \theta
$$

Where:

$D=$ The crystalline size

$k=$ The shape factor $(0.89)$

$\lambda=$ The laser source wavelength $(1.5406 \AA$ for $\mathrm{Cu} \mathrm{K \alpha})$

$\beta=$ The FWHM value of the peak

$\theta=$ The Bragg's angle

$d_{h k l}=a / \sqrt{ }\left(h^{2}+k^{2}+l^{2}\right)$

Where:

$d_{h k l}=$ The distance between the planes of atoms that give rise to the diffraction peaks

$a=$ The lattice parameter of the crystal lattice $h, k$ and $l=$ The Miller indices of the plane

Equation 2 was then used to calculate the lattice parameter of the synthesized samples. Value of $k$ was chosen for 0.89 for spherical crystal. Both the measured and calculated values were tabulated in Table 3. It was observed that the crystalline size of the RE-YIG NPs was within the range of $45-53 \mathrm{~nm}$. Besides that, we also found there has been a variation in $2 \theta$ and lattice constant value with different rare-earths dopants. It is speculated that the different ionic size of the rare-earth metals and yttrium contributes to such variation (Akhtar et al., 2017). Lattice constant increased in the sequence of YIG, Sm-YIG, NdYIG and La-YIG, corresponding to the increase in ionic size of the metal ions.

\section{Vibrating Sample Magnetometer Characterization}

Magnetic properties were studied by using VSM measurements performed at room temperatures. As observed in Fig. 3, RE-YIG shows soft magnetic material features, indicating the existence of superparamagnetic and single domain particles in the samples (Herzer, 1990; Kneller and Luborsky, 1963; Lu et al., 2007).
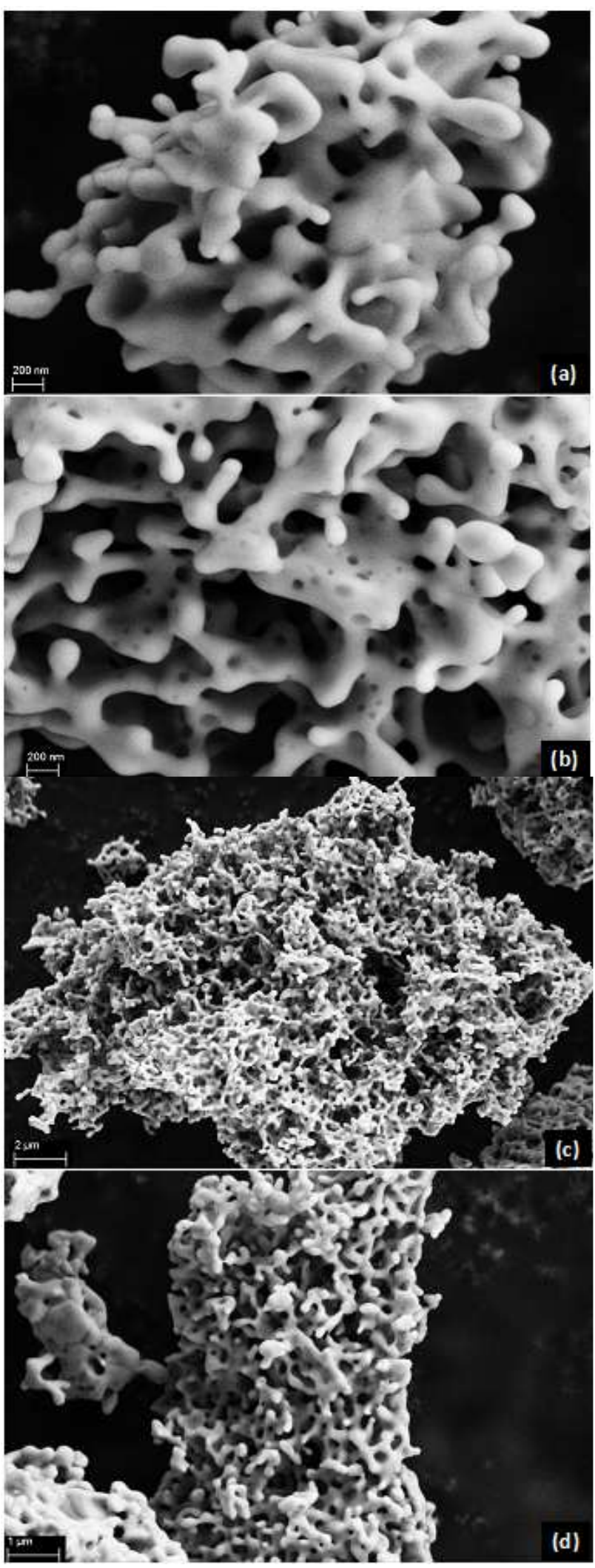

Fig. 1: FESEM Images for (a)YIG, (b) La-YIG, (c)Nd-YIG and (d)Sm-YIG 
Furthermore, as tabulated in Table 4 and Fig. 4, the magnetic saturation, $M_{s}$ of YIG decreases with the doping of $\mathrm{La}$ and increases with the doping of $\mathrm{Nd}$ and Sm, indicating $\mathrm{Nd}$ and $\mathrm{Sm}$ improve the parallel

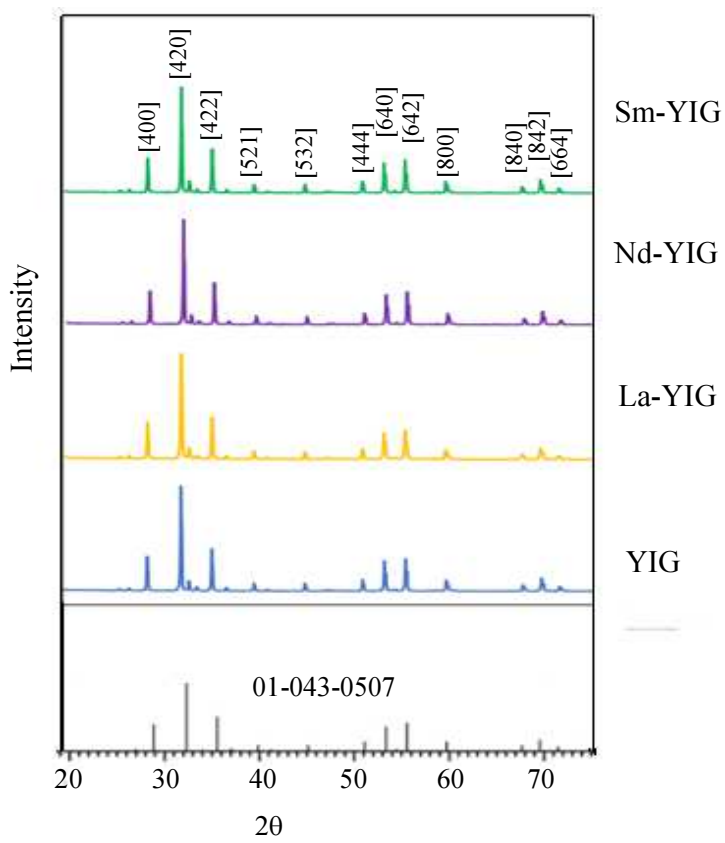

Fig. 2: XRD pattern of RE-YIG nanoparticles with YIG XRD reference magnetic moment alignment with $\mathrm{Y}$ ion in YIG structure (Uhm et al., 2016; Wolf, 1961).

Magnetic remanence $\left(\mathrm{M}_{\mathrm{r}}\right)$, coercivity $\left(\mathrm{H}_{\mathrm{c}}\right)$ and saturation $\left(\mathrm{H}_{\mathrm{s}}\right)$ has shown a general increase from YIG, La-YIG, Nd-YIG and Sm-YIG, following the order as per mentioned. The coercivity was observed to be increased as well. The $M_{s}$ for Sm-YIG from our previous study was only $20.3 \mathrm{emu} / \mathrm{g}$ for $\mathrm{x}=1.0$ (Lee et al., 2019). However, RE-YIG NPs are still considered as soft magnetic materials with $H_{c}$ less than 100 Oe.

\section{Evaluation of RE-YIG Nanofluids}

\section{Wettability Alteration Analysis}

Oil-wetting alteration were measured using inverted sessile drop contact angle measurement method with Goniometer. Based on Fig. 4, it is shown that La-YIG and Nd-YIG nanofluids have a slightly higher initial contact angle measurement than YIG nanofluid, whereas SM-YIG nanofluid shown significant reduction, without the irradiance of EM wave. It is suspected that the electrorheological properties of Sm-YIG nanofluids contributed to the significant difference. Overall, REYIG has shown a general reduction in oil-wetting angle, indicating a better performance of oil sweeping rate (Mohajeri et al., 2015).

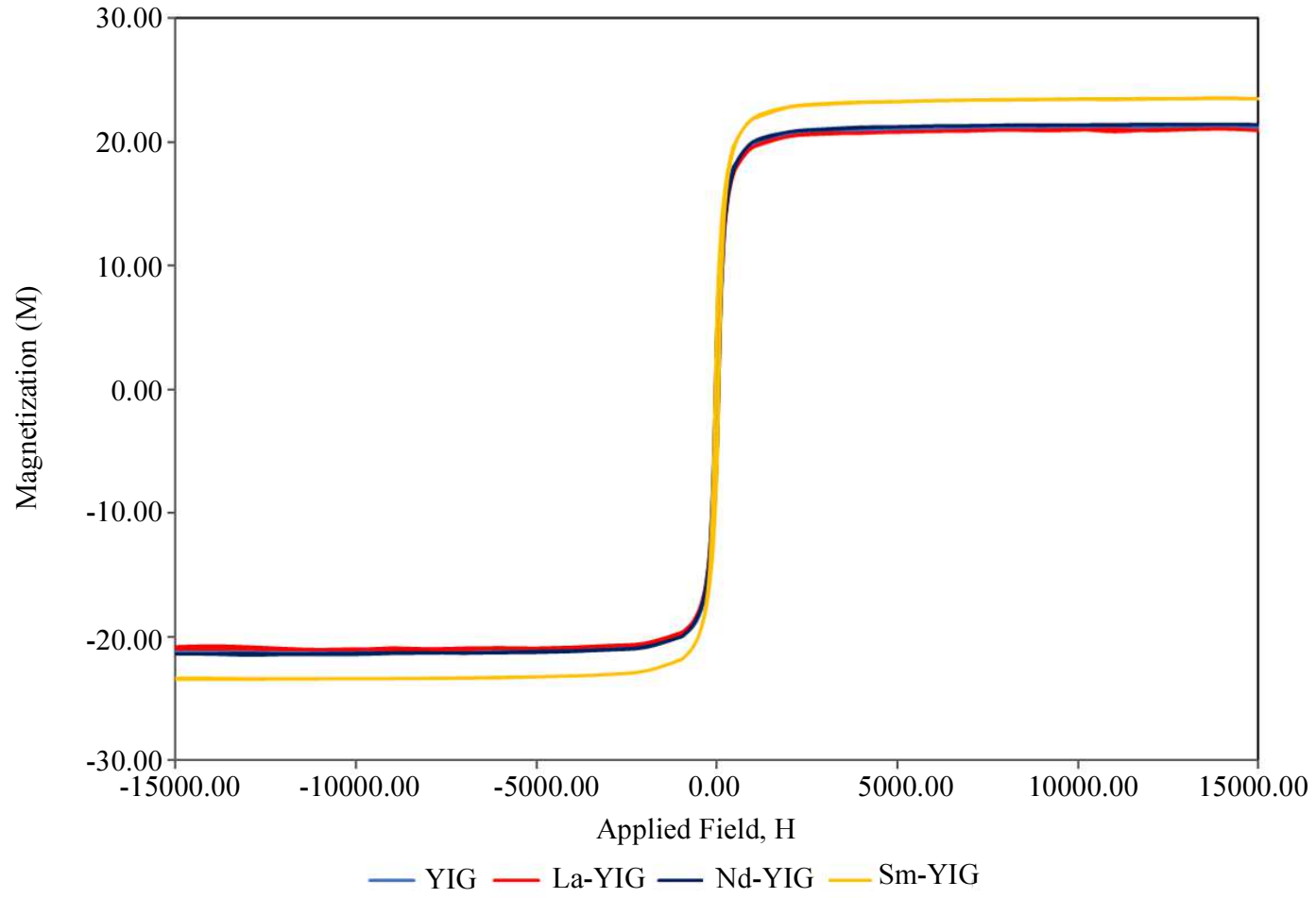

Fig. 3: Magnetic hysteresis loop of RE-YIG nanoparticles 


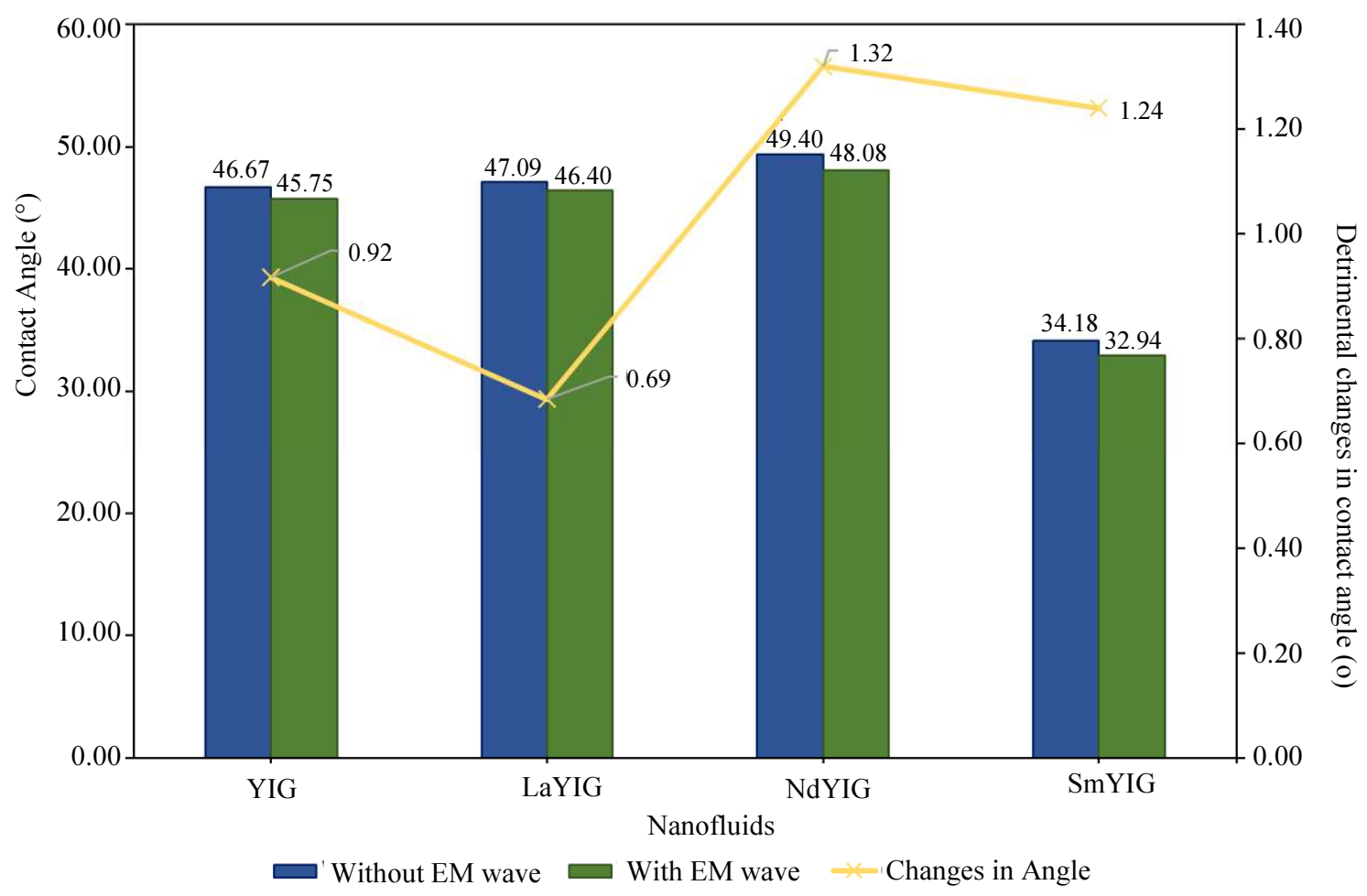

Fig. 4: Wettability alteration with RE-YIG nanofluids and influence of EM waves.

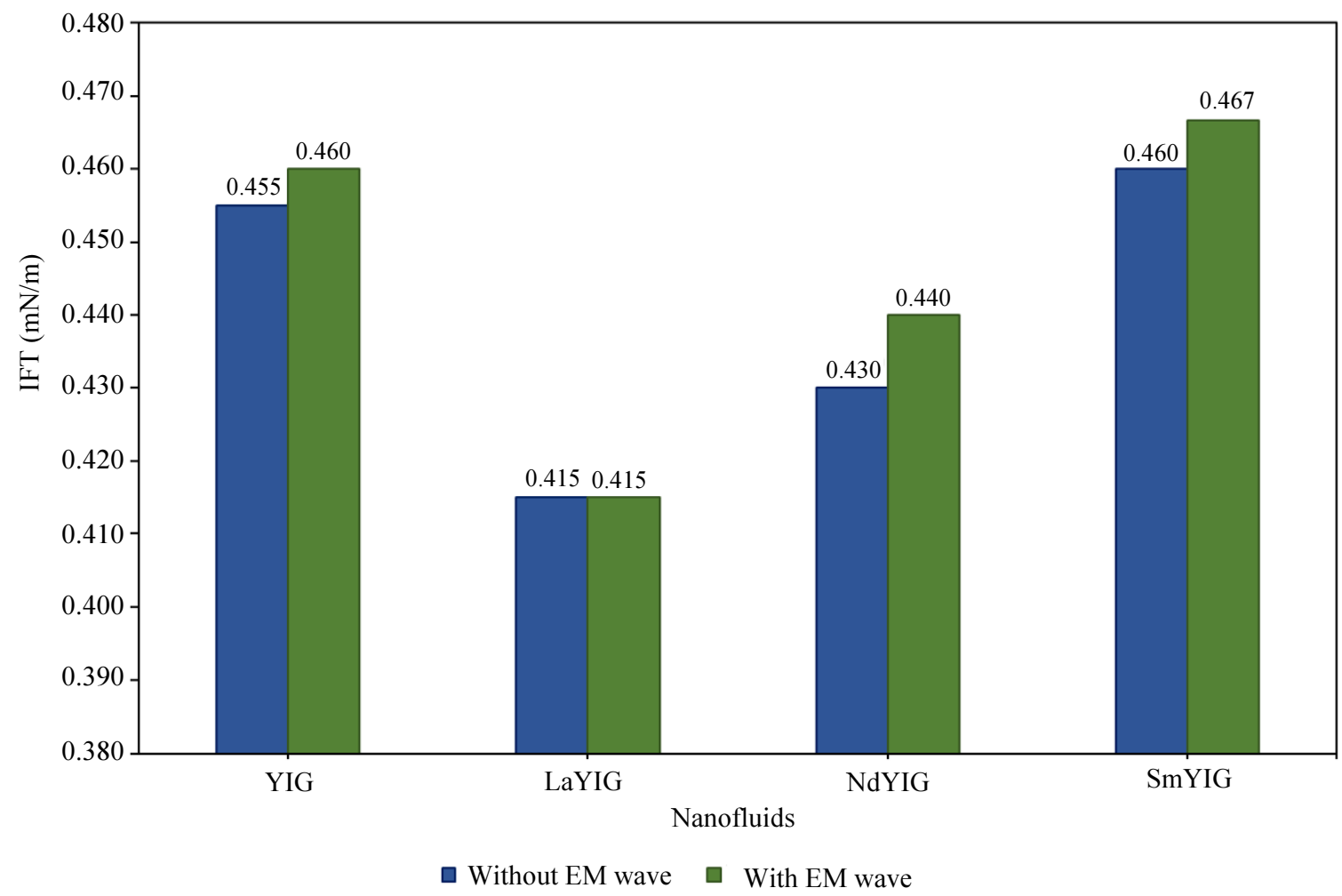

Fig. 5: IFT alteration with RE-YIG nanofluids and influence of EM waves 


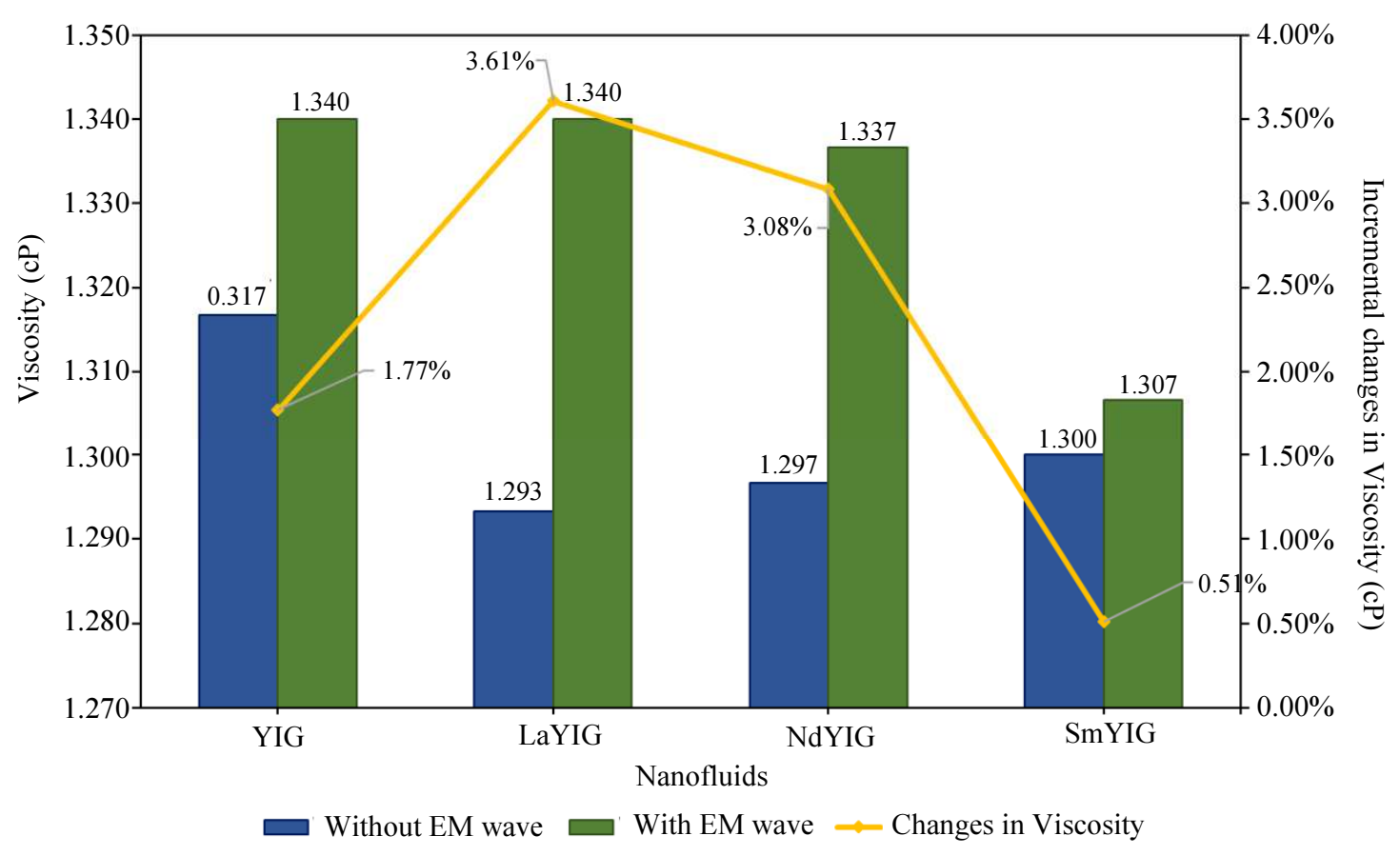

Fig. 6: Viscosity alteration with RE-YIG nanofluids and influence of EM waves

Table 3: XRD parameter of RE-YIG nanoparticles based on (420) peak

\begin{tabular}{llllll}
\hline Samples & $2 \theta$ & FWHM $\left(^{\circ}\right)$ & Crystalline size, $D(\mathrm{~nm})$ & $d$-spacing $(\AA)$ & Lattice constant, $a(\mathrm{~nm})$ \\
\hline YIG & 32.324 & 0.163 & 50.058 & 2.767 & 12.374 \\
La-YIG & 32.272 & 0.182 & 44.879 & 2.771 & 12.393 \\
Nd-YIG & 32.298 & 0.158 & 51.870 & 2.769 & 12.383 \\
Sm-YIG & 32.324 & 0.154 & 53.062 & 2.768 & 12.377 \\
\hline
\end{tabular}

Table 4: VSM analysis of RE-YIG nanoparticles

\begin{tabular}{lllll}
\hline & \multicolumn{1}{c}{ Magnetic parameters } & & \\
Samples & - & $M_{r}(\mathrm{emu} / \mathrm{g})$ & $H_{c}(\mathrm{Oe})$ & $H_{s}(\mathrm{Oe})$ \\
\hline YIG & $M_{s}(\mathrm{emu} / \mathrm{g})$ & 4.45 & 37.09 & 1395.97 \\
La-YIG & 21.30 & 4.41 & 39.68 & 1429.42 \\
Nd-YIG & 21.10 & 5.25 & 46.05 & 1464.67 \\
Sm-YIG & 21.50 & 6.02 & 47.03 & 1503.88 \\
\hline
\end{tabular}

\section{Interfacial Tension Alteration Analysis}

Based on Fig. 5, it is observed that the oil-nanofluid IFT results does not shows significant changes under the influence of EM wave. However, the IFT value does differ for different rare-earth dopants. La-YIG has the lowest IFT value whereas Sm-YIG has the highest IFT value. The increment in IFT value correspond to the increment of rare-earth metal ionic size, suggestive that the structural properties of REYIG is one of the contributors to the IFT alteration, where further studies is required.

\section{Viscosity Alteration Analysis}

As shown in Fig. 6, a similar trend of viscosity of REYIG without the influence of EM wave were observed as in IFT section, further suggesting that the structural properties of RE-YIG should be investigated. Under the irradiance of EM wave, each RE-YIG nanofluids shows different magnitude in changes of viscosity as well, with La-YIG having the largest increment, which is $3.61 \%$ followed by Nd-YIG. It is suspected that the structural distortion experienced by the YIG structure due to the doping of bigger ionic size metal ions and the magnetic coercivity of RE-YIG particle, contributes to the variation of incremental changes in viscosity. 


\section{Conclusion}

A high crystallinity $\mathrm{Y}_{2.8} \mathrm{R}_{0.2} \mathrm{Fe}_{5} \mathrm{O}_{12}(\mathrm{R}=\mathrm{La}, \mathrm{Nd}, \mathrm{Sm})$ with grain size ranging between $100-200 \mathrm{~nm}$ were synthesized successfully via the sol-gel auto-combustion method. XRD results showed variation in lattice parameter, suggesting the ionic radii of rare-earth metal ions contributed to structural distortion within the YIG structure which increased the overall lattice constant of the crystal structure. Nd-YIG and Sm-YIG shown improvement in YIG magnetization saturation value, with Sm-YIG being $23.54 \mathrm{emu} / \mathrm{g}$. Wettability data showed general improvement in reduction of oil-wetting contact angle, suggesting potential improvement in oil sweeping rate. Both IFT and viscosity data showed that the dopant of the YIG nanoparticles contributes to the changes in IFT and viscosity value without the irradiance of EM waves. Under the influence of EM waves, IFT value does not altered significantly. La-YIG showed the highest increment in viscosity value at $3.61 \%$ followed by Nd-YIG, YIG and Sm-YIG. Both structural and magnetic properties of REYIG are suspected to contribute to such changes, where further research studies are recommended.

In conclusion, the doping of rare-earth metal ions into YIG structure will change the various parameters and properties of the YIG nanoparticles and hence alter the IFT, wettability and viscosity when applied as nanofluids in EOR applications.

\section{Acknowledgement}

The author thanks Universiti Teknologi Petronas (UTP) for funding the project under the Yayasan UTP (YUTP) research grant.

\section{Funding Information}

This research is funded by Universiti Teknologi PETRONAS (UTP) under Yayasan UTP research grant with cost center number of $015 \mathrm{LC} 0-143$. The funders had no role in the design of the study; in the collection, analyses, or interpretation of data; in the writing of the manuscript, or in the decision to publish the results.

\section{Author's Contributions}

Lau Zhen Yin, Lee Kean Chuan, Beh Hoe Guan and Martin Weis: Conceptualization.

Lee Kean Chuan and Beh Hoe Guan: Funding Acquisition/Resources.

Lau Zhen Yin, Lee Kean Chuan and Beh Hoe Guan: Investigations/Methodology/Visualization/Writing.

Lee Kean Chuan, Beh Hoe Guan and Martin

Weis: Supervision/Validation/Review:

Hassan Soleimani: Superivision/ Valdation.

\section{Ethics}

This article is original and contains unpublished material. The corresponding author confirms that all of the other authors have read and approved the manuscript and no ethical issues involved.

\section{References}

Akhtar, M.N., M. Yousaf, S. Khan, M. Nazir and M. Ahmad et al., 2017. Structural and electromagnetic evaluations of YIG rare earth doped (Gd, Pr, Ho, Yb) nanoferrites for high frequency applications. Ceramics Int., 43: 17032-17040.

DOI: $10.1016 /$ j.ceramint.2017.09.115

Akhtar, M.N., M.A. Khan, M. Ahmad, G. Murtaza and R. Raza et al., 2014 Y3Fe5O12 nanoparticulate garnet ferrites: Comprehensive study on the syntesis and characterization fabricated by various routes. J. Magnetism Magnetic Materials, 368: 393-400.

DOI: 10.1016/j.jmmm.2014.06.004

Baqueiro, P., M. Lopez-Quintela, J. Rivas and J. Greneche, 1997. Annealing dependence of magnetic properties in nanostructured particles of yttrium iron garnet prepared by citrate gel process. J. Magnetism Magnetic Materials, 169: 56-68.

DOI: 10.1016/S0304-8853(96)00728-7

Bennetzen, M.V. and K. Mogensen, 2014. Novel applications of nanoparticles for future enhanced oil recovery. Proceedings of the International Petroleum Technology Conference (IPTC), At Kuala Lumpur, Malaysia. DOI: 10.2523/IPTC-17857-MS

Bhatia, K.H. and L.P. Chacko, 2011. Ni-Fe Nanoparticle: An innovative approach for recovery of hydrates. Brasil Offshore, Macae, Society of Petroleum Engineers, Brazil. DOI: 10.2118/143159-MS

Herzer, G., 1990. Grain size dependence of coercivity and permeability in nanocrystaline ferromagnets. IEEE Trans. Magnetics, 26: 1397-1402. DOI: $10.1109 / 20.104389$

Janifer, M.A., S. Anand, M. Senthuuran and S. Pauline, 2017. Effect of synthesis conditions on Yttrium Iron Garnet (YIG) nanocrystalline powder via sol-gel method. Int. Res. J. Eng. Technol.

Kneller, E.F. and F.E. Luborsky, 1963. Particles size dependence of coercivity and remanence of single domain particles. J. Applied Physics, 34: 656-656. DOI: $10.1063 / 1.1729324$

Lee, K.C., M.N.M. Sukri, B.H. Guan, H.M. Zaid and H. Soleimani, 2019. Interfacial tension and viscosity alteration of samarium doped Yttrium Iron Garnet (YIG) nanofluid under the presence of electromagnetic waves. Defect Diffusion Forum, 390: 64-70. 
Lu, A.H., E.L. Salabas and F. Schuth, 2007. Magnetic Nanoparticles: synthesis, protection, Functionalization and application. Angewandte Chemie Int. Edition, 46: 1222-1244. DOI: $10.1002 /$ anie. 200602866

Mohajeri, M., M. Hemmati and A. Sadat Shekarabi, 2015. An Experimental study on using a Nanosurfactant in an EOR process of heavy oil in Fractured Micromodel. J. Petroleum Sci. Eng., 126: 162-173. DOI: $10.1016 /$ j.petrol.2014.11.012

Ogolo, N.A., O.A. Olafuyi and M.O. Onyekonwu, 2012. Enhanced oil recovery using Nanoparticles, SPE Saudi Arabia section technical symposium and exhibition, Al-Khobar, Saudi Arabia. Society of Petroleum Engineers.

Peng, B., J. Tang, J. Lui, P. Wang and B. Ding et al., 2017. Applications of Nanotechnology in Oil and gas Industry: Progress and Perspective. Canadian J. Chemical Eng., 96: 91-100.

DOI: $10.1002 /$ cjce. 23042

Pilkington, G.A. and H.B. Wuge, 2012. Nanofluids mediating surface forces. Advances Colloid Interface Sci., 179-182: 68-84.

DOI: $10.1016 /$ j.cis.2012.06.007

Ristić, M., I. Nowik, S. Popović, I. Felner and S. Musić, 2003. Influence of synthesis procedure on the YIG formation. Materials Letters, 57: 2584-2590.

Ryoo, S., A.R. Rahmani, K.Y. Yoon, M. Prodanovic and C. Kotsmar et al., 2012. Theoretical and experimental investigation of the motion of multiphase fluids containing paramagnetic nanoparticles in porous media. J. Petroleum Sci. Eng., 81: 129-144.

DOI: $10.1016 /$ j.petrol.2011.11.008

Sanchez, R., J. Rivas, P. Vaqueiro, M. Lopez-Quintela and D. Caeiro, 2002. Particle size effects on magnetic properties of yttrium iron garnets prepared by a sol-gel method. J. Magnetism Magnetic Materials, 247: 92-98. DOI: 10.1016/S03048853(02)00170-1

Soares, F.S.M., M. Prodanovic and C. Huh, 2014. Excitable nanoparticles for trapped oil mobilization. SPE Improved Oil Recovery Symposium, Tulsa, Oklahoma, Society of Petroleum Engineers.

Soleimani, H., M.K. Balg, N. Yahya, L. Khodapanah and M. Sabet et al., 2018. Synthesis of $\mathrm{ZnO}$ nanoparticles for oil-water interfacial tension reduction in enhanced oil recovery. Applied Physics A, 124: 128-128. DOI: 10.1007/s00339-017-1510-4
Soleimani, H., N. Yahya, N.R. Latiff, H.M. Zaid and B. Demiral et al., 2014. Novel enhanced oil recovery method using $\mathrm{Co} 2+\mathrm{xFe} 2+(1-\mathrm{x}) \mathrm{Fe} 3+2 \mathrm{O} 4$ as magnetic nanoparticles activated by electromagnetic waves. J. Nano Res., 26: 111-116.

DOI: 10.4028/www.scientific.net/JNanoR.26.111

Soleimani, H., N.R. Latiff, N. Yahya, M. Sabet and L. Khodapanah et al., 2016. Synthesis and Characterization of Yttrium Iron Garnet (YIG) Nanoparticles activated by Electromagnetic wave in Enhanced Oil Recovery. J. Nano Res., 38: 40-46. DOI: 10.4028/www.scientific.net/JNanoR.38.40

Uhm, Y.R., J.C. Lim, S.M. Choi and C.S. Kim, 2016. Magnetic properties of R-YIG ( $\mathrm{R}=\mathrm{La}, \mathrm{Nd}$ and $\mathrm{Gd})$ derived by a sol-gel method. J. Magnetics, 21: 303307. DOI: 10.4283/JMAG.2016.21.3.303

Vajargah, S.H., H.M. Hosseini and Z. Nemati, 2006. Synthesis of nanocrystalline yttrium iron garnets by sol-gel combustion process: The influence of $\mathrm{pH}$ of precursor solution. Materials Sci. Eng. B, 129: 211215. DOI: 10.1016/j.mseb.2006.01.014

Vajargah, S.H., H.M. Hosseini and Z. Nemati, 2007. Preparation and characterization of Yttrium Iron Garnet (YIG) nanocrystalline powders by autocombustion of nitrate-citrate gel. J. Alloys Compounds, 430: 339-343. DOI: $10.1016 /$ j.jallcom.2006.05.023

Wolf, W., 1961. Ferromagnetic alignment by antiferromagnetic exchange interaction, note on the magnetic behaviour of neodymium garnet. J. Applied Physics, 32: 742-742. DOI: $10.1063 / 1.1736086$

Yahya, N., M. Kashif, A. Shafie, H. Soleimani and H.M. Zaid et al., 2014. Improved oil recovery by high magnetic flux density subjected to iron oxide nanofluids. J. Nano Res., 26: 89-99.

DOI: 10.4028/www.scientific.net/JNanoR.26.89

Yuan, Y. and T.R. Lee, 2013. Chapter 1: Contact angle and wetting properties. Surface Sci. Techniques, 51: 3-34. DOI: 10.1007/978-3-642-34243-1_1

Zaid, H.M., N.R. Latiff, N. Yahya, H. Soleimanil and A. Shafie, 2014. Application of electromagnetic waves and dielectric nanoparticles in enhanced oil recovery. J. Nano Res., 26: 135-142. DOI: $10.4028 /$ www.scientific.net/JNanoR.26.135

Zitha, P.L.J. and F. Wessel, 2002. Fluid flow control using magnetorheological fluids, SPE/DOE improved oil recovery symposium. Tulsa, Oklahoma, USA, Society of Petroleum Engineers. 